\title{
LA AUTOGESTIÓN DE LA PANDEMIA COVID-19 EN LOS PUEBLOS ORIGINARIOS DE OAXACA, MÉXICO
} Original Peoples of Oaxaca, México, and Self-determination of COVID-19 Pandemic

\section{ALICIA BARABAS*}

Fecha de recepción: 11 de agosto de 2020 - Fecha de aprobación: 28 de octubre de 2020

\section{Resumen}

Este trabajo intenta proporcionar una mirada etnográfica sobre un ejemplo de acción colectiva emprendida por los pueblos originarios del Estado de Oaxaca, en México, para prevenirse y afrontar la pandemia COVID19. Presentaré con detalle el caso de Santiago Comaltepec, un municipio en la Sierra Norte habitado por indígenas chinantecos; lo que piensan, las decisiones que toman y las acciones que realizan para enfrentar la pandemia. La gestión autónoma comunitaria es posible gracias al ejercicio de las formas tradicionales de elección y gobierno, llamadas en 2001 Sistemas Normativos Internos (SNI), legalizados en la Constitución de Oaxaca desde 1995 con el nombre de Usos y Costumbres. Sugiero que este sistema es una "utopía concreta" en proceso de construcción colectiva.

Palabras clave: Pandemia COVID-19; pueblos originarios; sistemas normativos internos; Estado de Oaxaca, México.

\section{Abstract}

This paper try to give an ethnographical look over a positive exemple of collective actions address by originals peoples of Oaxaca state, in Mexico, to prevent and overcome the pandemic COVID-19. I shall present with detail the case of Santiago Comaltepec, a municipality at the Sierra Norte inhabited by chinantec indians; what they think, the decisions they make and the actions they take to confront it. The autonomous community responses are posible beacause the exercise of traditional forms of election and government, called in 2001 internal normative systems (SNI), legalize at the Constitution of Oaxaca State from 1995 with the name Usos y Costumbres 1995. I suggest this system is a "concrete utopia" in process of collective construction.

Keywords: COVID-19 pandemic; original peoples; internal normative systems; State of Oaxaca, Mexico. 
La pandemia está dejando en claro que existen grandes desigualdades entre países y dentro de los países pero que, en mayor o menor medida, todos los sistemas de salud están en crisis en el mundo actual. También nos muestra las diferencias culturales existentes entre y dentro de los Estados nacionales con respecto a las nociones de enfermedad, salud, bienestar, muerte, y a los valores atribuidos a la prevención y el cuidado individual y colectivo. Este artículo no aspira a explorar estas categorías profundas de las culturas, sino a proporcionar información etnográfica sobre un ejemplo de acción colectiva, fundada en esos valores y nociones, emprendida por los pueblos originarios de Oaxaca para prevenirse y superar el contagio de COVID-19.

Una crisis planetaria como esta puede dar lugar a divagaciones, especulaciones y predicciones negativas o positivas sobre el mundo posible posterior a ella. Si bien es cierto que las crisis, de diversa naturaleza, han producido cambios fundamentales en las sociedades, no tenemos que confundir aspiraciones $y$ expectativas con posibilidades reales o con tendencias a largo plazo. Es válido imaginar y proponer futuros, pero me parece preferible "mirar" -en el sentido de la mirada antropológica de la que hablaba Roberto Cardoso de Oliveira (1998)- lo que existe alrededor de nosotros y que puede ser motivo de reflexión y ejemplo a tomar en cuenta. Por ello, después de un contexto de la pandemia, voy a referirme a lo que piensan, las decisiones que toman y las acciones que realizan los pueblos originarios en el estado de Oaxaca para enfrentarla.

\section{La pandemia COVID-19}

El COVID-19 marca un antes y un después, una fractura en las formas de vida de la sociedad mundial, una crisis de tal magnitud que es vivida por muchos como una catástrofe de proporciones apocalípticas. Se trata de un extenso tiempo liminal, de temor, incertidumbre e inseguridad, pero también de "espera-esperanza”, como diría el filósofo Ernst Bloch (1980 [1959]): un umbral hacia algo que se espera sea diferente y mejor que las sociedades en las que vivíamos antes.

Muchos piensan ahora que el origen de la pandemia está en el mundo globalizado y que es ineludible un replanteo de los valores que han llevado a la pobreza, la injusticia, la desigualdad y el deterioro ambiental. Las carencias de la mayoría han empeorado con la crisis sanitaria porque ha crecido la desigualdad preexistente y se han generado otras. Los pobres, más pobres ahora, son los que primero sufren el deterioro económico y tienen menos condiciones para practicar las medidas de prevención y para acceder al sistema de salud en caso de contagio. En ese contexto, la mirada se vuelca hacia las comunidades locales con solidaridad interna y vínculos de cooperación que mantienen relaciones no extractivistas con la tierra y el medio ambiente, que no son productivistas ni consumistas y que pueden desarrollar explotaciones e industrias autosustentables de pequeña y mediana escala en lugar de megaproyectos lesivos para la naturaleza y para las culturas locales. Lo sugerente es que en la búsqueda de cambios profundos, las expectativas en todo el mundo se orientan a revisar la experiencia histórica de las comunidades indígenas. 
¿Qué futuro puede entreverse para el momento en que esta pandemia ceda? Ahora el futuro es una conjetura, como dice Tokatlian (2020), y no es posible dar una respuesta unívoca. Pienso que en el futuro inmediato -o hasta que circule mundialmente una(s) vacuna(s) contra las cepas del coronavirus para todos- pueden tomarse diferentes cursos de acción para evitar nuevos brotes, reorganizar la economía, mejorar la tecnología virtual que será indispensable, etc. Sin embargo, me parece poco probable que se produzcan transformaciones radicales encaminadas a cambiar el sistema neoliberal vigente por otro fundado en la equidad, la justicia y la sostenibilidad.

De ser así, en el futuro iremos regresando a lo que conocíamos, aunque con nuevas prácticas protectivas y de conducta interpersonal y social que llegaron para quedarse y, sería deseable, con mayores consensos acerca de los cambios estructurales necesarios que la pandemia ha sacado a la luz. Pero, también puede esperarse una dinámica opuesta, que muestra un presente y un futuro en nada mejores que el mundo anterior a la pandemia, como nos dice Néstor García Canclini (2020) cuando habla del tránsito de un capitalismo de la precariedad a un capitalismo de la prescindibilidad, que deriva a los jóvenes hacia las organizaciones mafiosas ante la imposibilidad de acceder a un empleo.

Esta temporalidad ambigüa en la que vivimos puede ser propicia para la imaginación creadora y la construcción de utopías, entendidas como una dimensión de lo posible y no como algo falso o irrealizable (Barabas, 1989). Bloch decía, en El principio esperanza (1980 [1959]), que entre las condiciones históricas propicias para el surgimiento del pensamiento utópico en la sociedad están la vivencia y la conciencia de una crisis múltiple, que pone en entredicho la legitimidad de la realidad establecida y encamina a los inconformes a la construcción de nuevas y mejores formas de sociedad. No me refiero a las utopías abstractas, conocidas como "novela política", que Bloch entendía como creaciones intelectuales de nuevas sociedades, ideas relevantes pero alejadas de las aspiraciones populares, sino a las utopías concretas, que Bloch (1980 [1959]) definía como "la potencia anticipadora de lo que los deseos y las acciones colectivas lograrán en el futuro, siempre mediados por las condiciones históricas" (p.353).

Pienso que en México existen utopías concretas en construcción, o "epistemologías experienciales”, como diría Boaventura de Sousa Santos (2018, p. 307). Una de ellas son las formas autonómicas de gobierno y de gestión de los pueblos originarios de Oaxaca, que se ejercen en 417 de los 570 municipios de este estado, autodeterminados a través de sus sistemas normativos internos, legalizados en la Constitución del Estado de Oaxaca desde 1995 con el nombre de "usos y costumbres", término que reflejaba una visión folclórica de las culturas y que fue reemplazado en 2001 por el de sistemas normativos internos (SNI), con el fin de jerarquizarlos vinculándolos con la cosmología y la ética culturales.

\section{El coronavirus en el Estado de Oaxaca}

En Oaxaca, al igual que en muchos otros estados del país, la intelectualidad critica con fuerza la figura del Estado frente a la pandemia porque se ha mostrado poco eficaz y oportuno en la información proporcionada y en la toma 
de decisiones. Con todo, el Estado, la Secretaría de Salud, la seguridad sanitaria pública, la medicina privada organizada por el Estado y las fuerzas armadas han tomado un papel preponderante en la gestión de la pandemia y dejado en segundo plano, o sin intervención, a la Iglesia y las organizaciones no gubernamentales (ONG), que son actores principales en otros problemas críticos, como los migrantes o la defensa de territorios indígenas. Más allá de los cuestionamientos, el Estado ha acrecentado y revalorizado su papel.

El imaginario urbano en torno al coronavirus es variado, pero la opinión que más se escucha es que la pandemia es falsa, que es un invento del gobierno para "acabar con los pobres, porque reciben dinero por ellos". Se viralizan rumores de que la sanitización de espacios públicos en realidad esparce el coronavirus por el aire para "contagiar a todos de una vez". Al pensar que quieren matarlos, algunos reaccionan con violencia. Otros dicen que los mexicanos no se van a enfermar porque comen comida buena, sana, tortillas, chile, etc., y porque "no comen bichos vivos como los chinos que se infectaron con este virus". Por estas razones, muchos no toman en serio las medidas preventivas y protectivas. Los gobiernos y los medios insisten en decir que hay que quedarse en casa y trabajar o estudiar desde allí. Sin embargo, muchos ven el confinamiento como un tiempo vacacional y otros como una prohibición absurda porque han quedado sin trabajo y deben salir cotidianamente a buscarlo.

En nuestro estado, al igual que en la mayoría de los otros 31 que integran la República, se sigue el modelo de prevención establecido por la federación; de allí que todos los espacios públicos, escuelas, universidades, oficinas estatales y de empresa privada, lugares de entretenimiento, industrias, empresas y comercios no esenciales están cerrados desde el 23 de marzo de 2020. El 10 de agosto la situación casi no ha variado y el gobierno recomienda el confinamiento, aunque ha permitido el reinicio de algunas actividades. Lo que se observa es que durante estos meses buena parte de la población de la ciudad de Oaxaca y otras ciudades del estado no ha cumplido con el confinamiento y se moviliza cada día porque la subsistencia depende del trabajo diario. En las calles no todos guardan la distancia debida o utilizan cubreboca y es poco el cuidado que se presta a los indígenas en la ciudad. Por ejemplo, en abril, para cobrar el apoyo que les da el Programa de Fomento a la Agricultura, cincuenta indígenas, casi todos mayores, pasaron la noche acostados en la banqueta, afuera de un banco, en el centro histórico de Oaxaca, esperando que les dieran un turno para ser atendidos el siguiente día, ya que vienen de poblados del interior del estado.

Desde el 9 de abril, la Secretaría de Salud (SS), a través del Instituto Nacional de los Pueblos Indígenas (INPI), dio a conocer las medidas oficiales de prevención en 42 de los 68 idiomas indígenas reconocidos en México, las cuales se difundieron a través de 22 radiodifusoras culturales, pero solo en los medios rurales y no en las ciudades (Hobarth \& García, 2020). Esas medidas fueron las mismas para toda la población nacional: lavarse las manos con agua y jabón, usar alcohol diluido en agua y gel antibacterial, cubreboca, guardar la distancia y quedarse en casa si es posible. En Oaxaca, la ONG CIELO (Organización de Comunidades Indígenas en Liderazgo), una red de 200 traductores de 30 lenguas indígenas que surgió en Estados Unidos en 2020, pero cuyos intérpretes 
estaban relacionados desde mucho antes con el Frente Indígena Oaxaqueño Binacional (FIOB), ha difundido videos/audios informativos en algunas de las variantes dialectales de los idiomas mixe, chatino, chinanteco, amuzgo, triqui, mixteco y zapoteco.

La información que se proporciona en México acerca de la adscripción étnica de los contagiados, curados o fallecidos es, más que mínima, invisible. Un cuestionario aplicado por Horbarth y García (2020) a los estados, los pueblos indígenas y otros agentes, señala que es la Secretaría de Salud quien debe preguntar a los enfermos que llegan a los hospitales si hablan alguna lengua indígena, omitiendo preguntar por la autoadscripción y adscripción por consanguineidad, que son criterios también utilizados en el censo nacional de población para definir quién es indígena y que elevan su número de nueve a veinticinco millones de personas (INEGI, 2010).

Un gran problema es que el número de población indígena nacional no está actualizado, ya que el censo de 2020 no pudo ser completado. Las referencias estadísticas anteriores tienen alguna utilidad para las regiones y municipios rurales, aunque no para el registro de los indígenas urbanos residentes y migrantes. En los estados es el INPI quien recoge la información de contagios y muertes a través de sus 110 centros coordinadores, la trasmite a la SS de cada estado y estas a la Secretaría de Salud a nivel federal. En los hechos, ni la Secretaría de Salud ni el INPI informan al público sobre los casos de indígenas enfermos y muertos por coronavirus en los medios rurales, y contabiliza a los indígenas urbanos como población sin adscripción étnica, aunque se conoce un registro del 31 de mayo que reporta para
Cancún 43 contagiados, para Tijuana 130 y para la ciudad de México 14, y un total nacional de 1.165; todos ellos fallecidos (Hobart \& García, 2020).

Las absurdas cifras anteriores dejan ver que los registros hospitalarios no reflejan la realidad, tanto porque en la mayor parte de los casos no se pregunta por el idioma hablado como porque son pocos los indígenas que llegan a un hospital que atiende enfermos de COVID-19, ya que en las zonas rurales existen escasos servicios sanitarios a los que acudir y en las urbes no tienen los medios que les permiten ser aceptados y atendidos. De allí que sea muy difícil cualquier estimación global de afectados en los 68 grupos etnolingüísticos del país. En Oaxaca, solo el que conoce las regiones y los municipios donde se ubican cada uno de los 16 pueblos indígenas puede inferir con cierta aproximación a qué pueblo pertenecen los afectados. En la misma situación están los demás estados de la federación, por lo que podríamos pensar en una invisibilización -deliberada o no-de los indígenas en el contexto de la pandemia.

Si bien se habla en forma genérica de que los indígenas constituyen el contingente más vulnerable, por estar en la pobreza y extrema pobreza y sin servicios médicos accesibles, no se conocen estadísticas que muestren cuál es la afectación real en cada uno de los pueblos originarios. Una consecuencia de la carencia de información sobre contagiados y fallecidos en cada grupo indígena es la ausencia de políticas públicas destinadas a mitigar y superar los efectos múltiples de la pandemia. Las acciones del INPI y de los gobiernos estatales son asistenciales (entregan paquetes de comida para los niños en algunos lugares) y de emergencia, como el abastecimiento ocasional de agua y 
comida y la recuperación de los cuerpos de los difuntos que no han llegado a un hospital.

Las cifras de nuevos contagios y de defunciones que vemos en el mapa interactivo de coronavirus por municipio, que prepara diariamente la Secretaría de Salud, nos indican que resulta fundamental diferenciar la evolución de la epidemia en medios urbanos, en particular en la ciudad capital, de la situación en medios rurarles.

Los primeros son espacios habitados principalmente por población no indígena, aunque son numerosos los indígenas de todos los grupos del estado que viven en las ciudades por diferentes motivos (carencia de tierra y trabajo, cuestiones de violencia en sus comunidades de origen o mejores oportunidades de estudio o comercio). Se sabe que gente de la misma procedencia puede ubicarse en un mismo barrio para tener vecindad con sus paisanos, pero usualmente los que llegan de sus comunidades sin apoyo parental se ubican donde pueden y conforman barrios interétnicos.

Con frecuencia se trata de población de escasos recursos o de migrantes más o menos recientes que viven en barrios informales en las periferias o en terrenos ocupados ilegalmente, que día a día buscan trabajos informales y que no pueden hacer caso del pedido gubernamental de confinamiento porque no tienen reservas de comida ni monetarias. A la tradicional escasez alimentaria se suma que los comedores públicos para los pobres están cerrados o desabastecidos. Por lo común, los barrios y las viviendas que habitan no cuentan con servicios de agua entubada, electricidad o drenaje, las casas son precarias, de un ambiente o dos, construidas a veces con materiales de desecho. En ellas viven familias ampliadas que no pueden guardar la "sana distancia" (dos metros) ni el confinamiento familiar ni comunitario.

Un aspecto crucial que opera en contra de los indígenas urbanos es que, al no vivir en comunidad, no tienen sistemas normativos propios que les permitan organizarse colectivamente y afrontar los riesgos y las crisis, como esta del coronavirus. Son indígenas descomunalizados (aunque en sus comunidades de origen estos sistemas estén vigentes) y no organizados en sus nuevos lugares.

Pero también hay indígenas oriundos en muchos de los 21 municipios que hoy conforman la extensa zona metropolitana de Oaxaca de Juárez, la ciudad capital del estado, pertenecientes a los distritos de Zaachila, Etla, Zimatlán y Tlacolula, en los Valles Centrales. Son más urbanos que rurales y de variada composición étnica, aunque suele predominar población que reconoce antepasados zapotecos o mixtecos, pero que ya no habla la lengua materna ni se considera indígena. Sin embargo, por su origen étnico, han decidido regirse por sistemas normativos internos, si bien estos suelen ser laxos y estar más o menos interferidos por intereses políticos partidarios y privados sobre la tierra. Esta población, que no puede comprar cubrebocas o gel antibacterial, viaja diariamente hacia la ciudad en autobuses, codo a codo con mucha gente en las mismas condiciones de vulnerabilidad, y son pocos los que cuentan con algún sistema formalizado de salud pública. En esta situación, las cifras de la epidemia en Oaxaca de Juárez y la zona metropolitana crece día a día. 


\section{Municipios con sistemas normativos internos}

Los espacios rurales están habitados por poblaciones indígenas principalmente, aunque muchas de las cabeceras distritales, y algunas de las municipales, en el interior del estado, son urbanas y albergan numerosa población con diversas adscripciones sociales y étnicas, incluidos indígenas de distintos grupos. En esas localidades - por ejemplo, en San Juan Bautista Tuxtepec, en la región Papaloapan; Huajuapan de León, en la Mixteca Baja; Juchitán y Salina Cruz, en el Istmo- no ha habido aislamiento comunitario y los casos de contagio iban más allá del centenar en el mes de julio.

La situación rural es diferente a la urbana principalmente porque la mayoría de los gobiernos municipales se reconocen de "costumbre" y pertenecen a alguno de los dieciséis pueblos indígenas que habitan en Oaxaca. Una de sus exigencias ha sido siempre la no injerencia de partidos políticos, o del Estado, en las elecciones y el gobierno de los municipios de "costumbre". Son precisamente los sistemas normativos internos los que han permitido a los pueblos indígenas autogestionar y superar la pandemia. El cierre voluntario de las fronteras municipales y el confinamiento de la población han sido las herramientas principales que utilizaron -asamblea y autoridades- para gestionar la evolución de la pandemia de una manera favorable. Por lo menos en 213 de ellos no existía ningún caso de contagio hasta comienzos de junio. En el mes de agosto, la situación no ha variado sustancialmente.

Sin embargo, como los usos y costumbres varían de pueblo en pueblo, existen unos pocos ejemplos de municipios que decidieron no aislarse y celebraron sus fiestas patronales, como la comunidad zapoteca San Pedro Ixtlahuaca, en Valles Centrales, que en junio tenía 30 casos de contagios y un fallecido y aun así festejó a su santo patrono durante tres días (27 a 30 de junio) a pesar de las severas advertencias de la Secretaría de Salud de Oaxaca de que era inconveniente hacer la fiesta por la asistencia multitudinaria de gente de pueblos vecinos, como Atzompa, con muchos contagios, San Andrés Ixtlahuaca y San Pablo Cuatro Venados (Miranda, 2020). El mismo autor asistió a la fiesta del municipio mixe Santa María Alotepec, celebrada del 1 al 5 de mayo en honor de Jesús Nazareno, con jaripeo, corridas de toros, feria, baile, fuegos artificiales y multitud de asistentes, a pesar de la prohibición estatal.

Para no estigmatizar prejuiciosamente a los usos y costumbres es justo comentar que para las comunidades su fiesta patronal, muchas veces originada en la aparición milagrosa de un cristo, un santo o una santa, es una conmemoración muy importante por su carácter fundacional y constructor de identidad (Barabas, 2006). Puede compararse emotivamente con la fiesta de la patria de la Independencia, en septiembre, para el conjunto de los mexicanos. Si esta celebración puede conmemorarse, como ha indicado el presidente López Obrador, ¿por qué las comunidades tendrían que dejar de festejar sus fiestas emblemáticas?

Funcionarios y políticos, entre ellos el gobernador Murat, dicen en sus discursos que van a respetar los usos y costumbres porque "el aislamiento voluntario ha salvado a las comunidades". Sin embargo, la Defensoría de los Derechos Humanos del Pueblo de Oaxaca ha recibido 35 quejas por abuso de autoridad municipal, presentadas entre el 23 de marzo y 
el 1 de junio; 15 de ellas en contra de municipios regidos por sistemas normativos internos ubicados principalmente en el área metropolitana de la ciudad capital (Matías, 2020). Los motivos principales de queja son: restricción de la movilidad; suspensión del suministro de agua potable a los infractores; prohibición de entrar y salir de la comunidad; desprotección de los datos personales de los infectados; inacción frente a la pandemia; cobro excesivo de multas por no usar cubrebocas y no hacer caso al filtro sanitario. La defensoría arguye que, al cerrar las comunidades, aunque sea en forma voluntaria para la mayoría, ponen en riesgo el libre tránsito y la movilidad, así como la provisión de medicinas y alimentos.

\section{Sistemas normativos internos}

En el campo de lo político, los SNI se expresan en el escalafón de cargos político-religiosos. En cada municipio se organizan de una forma singular, pero todos ellos responden a una serie de principios generales, algunos de los cuales son propios de la estructura del municipio castellano impuesto durante la Colonia, mientras que otros devienen de formas organizativas previas reconfiguradas por los pueblos indígenas a lo largo del tiempo. En otros trabajos (Barabas \& Bartolomé, 1999; Bartolomé, 2008) proponíamos que la lógica política involucrada en los sistemas de cargos supone una proyección de las categorías parentales a la vida colectiva, ya que implica el acceso de grupos generacionales horizontales a las distintas posiciones.

Pero, los sistemas normativos internos no se limitan al ejercio de lo político, sino que incluyen también la gestión agraria, el ejercicio de la justicia en el nivel comunal, las formas de intercambio recíproco interfamiliares (para los trabajos de la milpa, la construcción de la vivienda, las fiestas familiares) e intracomunitarias (las fiestas del pueblo, el tequio o donación de trabajos para la comunidad), las prácticas religiosas relacionadas con la religión católica y los rituales vinculados con la montaña sagrada, heredados de la religión mesoamericana. En el campo de la cosmovisión, la narrativa muestra el lugar central que ocupa el sistema de cargos. Por ejemplo, entre los zapotecos de El Rincón, el escalafón se reproduce entre las entidades extrahumanas que habitan en los cerros, quienes también cumplen servicios comunitarios. Entre los zapotecos de Choapam, los nahuales, alter ego de poderosos especialistas rituales, que cuidan el pueblo durante la noche, siguen un escalafón y cumplen tareas asignadas, al igual que las autoridades municipales. Para los chatinos, los muertos tienen también un escalafón de autoridades en el inframundo donde moran, que es concebido como una réplica de la comunidad terrenal (Barabas, 2006).

En otro trabajo (Barabas, 2016) he argumentado que los sistemas normativos internos de los pueblos indígenas son parte fundamental de su estructura social y pueden entenderse como el conjunto de preceptos y regulaciones, sustentados en representaciones y valores colectivos, que son del conocimiento mayoritario, aplicados para regular los desempeños en la vida social y política y sancionar a los que atentan contra los ordenamientos establecidos. Ese cuerpo común de normas, o reglas de conducta, establece los derechos y las obligaciones y hace posible ordenar las relaciones entre las personas y marcar los límites entre las conductas aceptables y no aceptables. Idealmente es conocido y respetado por todos como su ley y opera como instrumento de control 
social, ya sea por autoconvencimiento acerca de su legitimidad o mediante coacción física (castigos, multas, cárcel) o simbólica (rechazo de los vecinos, burla pública).

Para comprender los sistemas normativos resulta muy importante el concepto de costumbre, ya que son los depositarios y ejecutores de esta, la cual se refiere a la cultura propia de cada uno de los pueblos; a su tradición, que la gente considera verdadera e indiscutible por haber sido heredada de los antepasados y que, por lo tanto, debe ser practicada y conservada a través de las generaciones. No cumplir con la costumbre puede acarrear desgracias individuales y colectivas.

La práctica de la reciprocidad en el intercambio de bienes y servicios es el motor de la acción social y la argamasa con la que se construyen los sistemas normativos indígenas. Es preciso ir más allá del concepto elaborado por Mauss (1925) y comprender la reciprocidad como una ética del don (Barabas, 2003), como el código moral que prima en los pueblos y que se refiere al conjunto de representaciones, valores y estipulaciones que orientan a la sociedad a relacionarse a partir de intercambios o dones recíprocos equilibrados en todos los ámbitos de la vida social y en la relación con las deidades. Para los pueblos indígenas la reciprocidad juega un papel clave en los procesos de desarrollo de los grupos domésticos, en la vida colectiva material y simbólica y en las formas de participación y acción social. En esta ética se ponen en juego valores fundamentales de los pueblos indígenas: el honor, el respeto, la palabra empeñada, el compromiso, la vocación de servicio, el nombre de la familia, el prestigio, la buena vecindad, la amistad, el afecto y el gusto por dar a los que se estima. Siendo así, la obligación de dar y devolver encontraría una determinación fuerte y profunda en los principios básicos de esa ética sociocultural que trazan las conductas deseables y prohibidas.

Estas formas de autogobierno local están integradas, por una parte, por la asamblea de comuneros o ejidatarios a la que pertenece gran parte de la población y, por la otra, por un escalafón de cargos políticos, religiosos y agrarios, que va desde los topiles, en el rango inferior, hasta el presidente municipal, en el superior. Muchas veces, por encima, se encuentran los ancianos, considerados sabios de respeto, que asesoran a las autoridades porque han cumplido satisfactoriamente todos los cargos del sistema y que muchas veces son también especialistas rituales. Los cargueros principales son los encargados, junto con los especialistas religiosos, de la reproducción de la antigua cosmología y dirigen los rituales relacionados con las ofrendas y los pedimentos en los cerros y manantiales, pero también toman parte en las celebraciones vinculadas con la iglesia, como las fiestas para el santo patrono y las mayordomías de los santos.

\section{El coronavirus desde la perspectiva de Comaltepec}

Santiago Comaltepec es un municipio chinanteco de poco más de dos mil habitantes, ubicado en la Sierra Norte, del que recibo noticias frecuente ${ }^{1}$. Lo que se decide en la asamblea, siempre por consenso, es ejecutado por el conjunto de autoridades y aprobado por los ancianos. El sistema normativo interno es muy fuerte no solo como sistema político, sino como pauta para la organización de la sociedad y la reproducción de la lengua y la cultura chinantecas. 
¿Por qué decidieron el blindaje en asamblea extraordinaria y legalizaron la decisión mediante un oficio? Porque sabiendo que ellos, así como la mayor parte de los municipios, no cuentan con un sistema de salud local ni regional, apostaron, en el mes de marzo, a evitar todo contagio, cancelando el acceso a los comaltepecanos radicados en la ciudad de Oaxaca, México y Estados Unidos que quisieran retornar, así como a visitantes, vendedores, maestros y cualquier extraño, como medida de protección de la salud de los vecinos frente a la pandemia. También se suspendieron las salidas de autobús y camioneta comunitaria que los transporta a comunidades vecinas y a la Central de Abastos de Oaxaca.

No se han empleado medios coercitivos para hacer cumplir las reglamentaciones porque la gente acata la decisión de las autoridades, ya que incumplir con alguna de ellas puede comprometer el buen nombre y el juicio que se tenga de alguien, pero se les anunció que de no acatarse podrían hacerse acreedores a sanciones, como multas o cárcel, mismas penalidades que emplean para otros malos comportamientos 0 delitos locales en tiempos normales.

La Regiduría de Salud, este año a cargo de una mujer, los comandantes mayores de vara, el Consejo de Vigilancia y los topiles se reunieron para acordar cómo ejecutar las medidas de sanidad recomendadas por la Secretaría de Salud de la Sierra Norte y decididas por el pueblo. Para lograr el cierre de los dos accesos viales y las veredas en el monte colocaron filtros sanitarios controlados por topiles. Las únicas personas autorizadas para salir y entrar son los comerciantes que venden productos de primera necesidad y necesitan abastecerse, y ellos deben avisar por escrito a la autoridad el día, hora y motivo de la salida, los lugares que visitarán, los productos que comprarán, el medio de transporte a utilizar, así como el horario de su regreso. Al retorno, en el filtro sanitario, los topiles revisan la temperatura de los que pasan y los invitan a lavarse las manos, colocarse gel antibacterial (que ellos preparan), cambiarse la ropa y desinfectar los productos que traen consigo. En otros municipios regidos por SNI, como la comunidad mixe Totontepec Villa de Morelos, todas las actividades comunitarias se realizan mediante tequios, entre ellos el tequio de las mujeres que preparan comida para dar a los que cruzan los filtros sanitarios (Nota de la Redacción, 2020).

A fin de prepararse para el aislamiento, las autoridades decidieron comprar toneladas de maíz y frijol para abastecer de lo indispensable a cada familia, pero se ayuda en especial a los ancianos y las mujeres solas con hijos. Colocaron tinajas de agua limpia y jabón en diversos puntos del pueblo para la higiene de la población, además de guardarse medidas sanitarias y de distancia entre sí. Con el mismo propósito de autoprotección se cancelaron todas las actividades relacionadas con la Semana Santa y, en mayo, estaba en duda la realización de la fiesta patronal de Santiago Apóstol. Tampoco se celebran misas, aunque mantienen abierta la iglesia permitiendo la entrada de cinco en cinco personas. En tiempos previos a la pandemia muchos hombres y menos mujeres salían con frecuencia para trabajar y los niños y jóvenes iban a la escuela. Ahora disponen de tiempo para ir al campo a recolectar zarzamoras de la época y prepararse para la siembra de maíz, frijol y otros productos y, lo que resulta muy importante, están enseñando a sus hijos las tareas del campo, conocimiento que estaba siendo relegado. Este año decidieron volver a 
celebrar a San Isidro, patrón del campo, el 15 de mayo, para pedirle la lluvia. Cabe enfatizar la sensatez de la decisión de asegurarse la autosuficiencia, al menos temporal, sin esperar ayuda del gobierno, pero también reconocer la rápida adaptación de las familias que, al disponer de tiempo, no dudaron en ampliar la dieta con bienes de recolección, se prepararon para lograr mejores cosechas de maíz y frijol y revitalizaron una fiesta dejada de lado por la urgencia del trabajo asalariado.

No es novedad que las representaciones sobre la salud y la enfermedad son diversas en las diferentes culturas y entre grupos dentro de ellas. En Comaltepec, la asamblea discutió sobre qué es el coronavirus, del que solo tenían la información general que se proporciona a todos los mexicanos, y decidieron que no era una enfermedad enviada por el Dueño del Cerro -entidad extrahumana territorial (Barabas, 2006)- debido a alguna transgresión cometida por miembros de la comunidad, ni tampoco era una enfermedad de "daño" enviada por algún brujo, dzá lüy, porque en esos casos habría personas de la comunidad ya enfermas. Concluyeron que se trataba de una enfermedad del exterior, de los otros, de las ciudades, y que la estrategia más adecuada para enfrentarla era el confinamiento comunitario voluntario hasta que pasara el peligro. Sin embargo, en algunas comunidades los vecinos prefieren cerrar la entrada a los fuereños al considerar que son peligrosos por ser citadinos y porque es en las ciudades donde se originó y creció el virus. No olvidemos el imaginario de temor y violencia que desatan en algunas comunidades rurales y en barrios urbanos pobres muchas de las acciones estatales encaminadas a la protección y prevención frente a la pandemia, como la fumigación sanitaria de los espacios públicos. En ese contexto, no es impensable que en el futuro el estigma del extraño alcance también a los antropólogos.

Desde el mes de marzo las autoridades buscaron contactos con los municipios aledaños para realizar acciones preventivas en común ya que, junto con otros 26 , forman parte de la Unión de Organizaciones de la Sierra Juárez de Oaxaca, y todos ellos decidieron seguir en confinamiento comunitario porque vieron que estaban en la misma situación vulnerable, sin fecha de apertura, con la consigna "salud comunitaria y cuidado mutuo dentro de la comunidad".

El 16 de mayo, el gobierno federal dio a conocer los 263 "municipios de la esperanza" y Oaxaca fue el que contó con el mayor número (213) sin ningún contagio. Esta nominación les permitía reiniciar todas las actividades y la movilidad, sin embargo, la mayor parte se negó a reabrir sus fronteras el 18 de mayo. Algunos de estos municipios reiniciaron ciertas actividades, pero poco después aparecieron los primeros contagios y volvieron a cerrar los accesos viales.

El 28 de junio circuló por las comunidades chinantecas de la Sierra un video en Facebook realizado por el médico Melitón Santiago, de Yolox, en el que da respuesta, en la variante de chinanteco de esta zona (para que entiendan los ancianos que no hablan español), a las preguntas que le han dirigido jóvenes de la región. Asegura, para los que no creen, que el coronavirus es una enfermedad que existe y que puede ser mortal. Explica cómo se contagia, cuáles son los síntomas, qué es la cuarentena y cuánto durará, cuáles son las 
precauciones a tomar ante la ausencia de vacuna y de tratamientos adecuados. Para el mismo día, las autoridades de Comaltepec convocaron una asamblea extraordinaria a la que asistieron 180 personas, realizada en la cancha municipal para guardar la debida distancia. Se explicó la importancia de mantener el confinamiento comunitario por un mes más, ya que la estrategia les ha dado buen resultado porque no tienen ningun caso de contagio. Algunos descontentos con el encierro fueron convencidos por sus vecinos y se aceptó la propuesta por votación unánime. Se tomaron otras resoluciones: la cancelación definitiva de la fiesta patronal del 25 de julio y el permiso a los estudiantes y avecindados, que habían quedado fuera de la comunidad al decidirse la cuarentena, para reingresar el 1 de julio, guardando 15 días de confinamiento domiciliario, pero no se autorizaron las visitas de comaltepecanos que no son residentes.

En los comienzos de agosto, en los municipios urbanos, como la ciudad de Oaxaca y la zona metropolitana, así como en las grandes y medianas ciudades del estado (Tuxtepec, Huajuapan de León, Juchitán, Salina Cruz), siguen creciendo los casos de contagio; más cuanto mayor es su tamaño y diversa su población. Paulatinamente se ha ido levantando el confinamiento y abriendo espacios públicos, de entretenimiento, comercios, restaurantes, aunque con restricciones y con medidas sanitarias, pero el nivel de contagios crece día con día.

\section{Para finalizar}

Los antropólogos sabemos que no deben aceptarse los preconceptos y los prejuicios atribuidos a los usos y costumbres indígenas porque se fundan en valores y actitudes racistas sustentadas básicamente en el desconocimiento del "otro cultural". Sin embargo, tampoco debemos idealizarlos y pensar que las comunidades son internamente homogéneas e igualitarias, que las relaciones interpersonales son idílicas y que están ausentes los conflictos agrarios, políticos o sociales. Las comunidades indígenas, al igual que cualquier otra sociedad, no están exentas de problemas y conflictos internos y con el exterior, pero esto no impide la existencia de múltiples lazos culturales comunitarios que les permiten accionar colectivamente para su beneficio.

El caso de Comaltepec y los demás municipios indígenas que se valen de sus sistemas normativos internos para paliar la crisis sanitaria deben verse como ejemplos positivos de la autogestión colectiva unida por el propósito de la sobrevivencia, sin la ayuda del Estado ni de otras instancias sociales o religiosas. Desde mi perspectiva, esta lección que nos brindan los pueblos indígenas de Oaxaca sobre el valor de las lealtades, la reciprocidad, la ayuda mutua, el respeto por su propia ley, la convivencia respetuosa con el medio ambiente y las formas productivas autosustentables de pequeña escala, puede convertirse en modelo a tomar en cuenta para la construcción de una nueva realidad social, como una opción para toda la sociedad. 


\section{Notas}

${ }^{1}$ Comunicaciones personales de Néstor Hernández López, autoridad municipal de Santiago Comaltepec, y Berenice Cortés Ramírez, doctoranda en ciencias del desarrollo regional, Instituto Tecnólogico de Oaxaca, 2020.

\section{Referencias bibliográficas}

Barabas, A. (1989). Utopías indias: Movimientos sociorreligiosos en México. México: Grijalbo.

(2003). La ética del don en Oaxaca: Los sistemas indígenas de reciprocidad. En Millán, S. \& Valle, J. (Coords.), La comunidad sin límites (pp. 39-64). México: Instituto Nacional de Antropología e Historia.

(2006). Dones, dueños y santos: Ensayos sobre religiones en Oaxaca. México: Porrúa, Instituto Nacional de Antropología e Historia.

(2016). Los sistemas normativos en los municipios indígenas. En Bartolomé, M. \& Barabas, A., Viviendo la interculturalidad: Relaciones políticas, territoriales y simbólicas en Oaxaca. México: Instituto Nacional de Antropología e Historia.

Barabas, A. \& Bartolomé, M. (Coords.). (1999). Configuraciones étnicas en Oaxaca: Perspectivas etnográficas para las autonomías. México: Consejo Nacional para la Cultura y las Artes, Instituto Naciona de Antropología e Historia, Instituto Nacional Indigenista.

Bartolomé, M. (2008). La tierra plural: Sistemas interculturales en Oaxaca. México: Instituto Nacional de Antropología e Historia.

Bloch, E. (1980 [1959]). El principio esperanza. Madrid: Aguilar.

Oliveira, R. C. de (1998). O trabalho do antropólogo. Sao Paulo: Paralelo 15 Universidade Estadual Paulista.

Santos, B. de S. (2018). Introducción a las epistemologías del sur. En Meneses, M. P. et al. (Eds.), Construyendo epistemologías del sur (pp. 303-342). Buenos Aires: Consejo Latinoamericano de Ciencias Sociales.
García Canclini, N. (2020). Las preguntas que hacen falta en los Zoom. Revista Periódico Reforma, 31 de mayo.

Hobarth, J. \& García, A. (2020). Efectos y contingencias de la pandemia COVID-19 en las comunidades rurales y urbanas de México. En Hobarth, J. \& García, A. (Coords.), Contribución continental al Informe del relator especial sobre los derechos de los pueblos indígenas y sobre el impacto del COVID-19 en los pueblos indígenas: Recopilacón de dieciocho contribuciones. México: Red de Investigadores sobre Indígenas Urbanos.

INEGI (2010). Censo General de Población. México: Instituto Nacional de Estadística y Geografía.

Matías, P. (2020). Integra Defensoría 35 quejas por abusos de autoridad contra ayuntamientos en tiempos de pandemia. Página Tres, 8 de junio.

Mauss, M. (1925). Essai sur le don: Forme et raison de l'échange dans les sociétés archaïques. L'Année Sociologique. París: Nueva Serie.

Miranda, F. (2020). Pese a contingencia municipio de Oaxaca celebra fiesta patronal de tres días. 29/6, El Universal, Estados.

Nota de la Redacción (2020). Pueblo mixe, ejemplo de organización para enfrentar el COVID-19. NSS Oaxaca, 8 de junio.

Tokatlian, J. G. (2020). Conjeturas después de la pandemia: El futuro después del COVID-19. Buenos Aires: Programa Argentina Futura. 